\title{
THE PRESENT SITUATION ON HYBRID TECHNIQUES IN HUNGARY ESPECIALLY IN HIGH FREQUENCY APPLICATIONS
}

\author{
AUREL SONKOLY and GYORGY WOLLITZER \\ Industrial Research Institute for Electronics, "HIKI", Budapest
}

(Received July 2, 1981; in final form October 20, 1981)

\section{INTRODUCTION}

To understand the development of hybrid techniques in Hungary we have to emphasise some specific features which may be unknown to readers.

1) A research institute and a factory, "HIKI" and "REMIX", are the only ones responsible for the development of hybrid technology in Hungary. This monopoly like situation has advantages and disadvantages. Since hybrid technology needs to meet first the domestic demands this means a situation without competition; nevertheless it results in a compulsion for the institute and the factory to alone perform all the tasks set by the Hungarian electronic industry.

2) We obtain all the problems to be solved with hybrid ICs from the industrial part of the electronics industry. The demand from the consumer electronic industry is still negligible.

3) In the initial period of research we have been compelled to develop technological and measuring equipment together with the technology itself and this tradition has not vanished. The old constraint resulted in a better knowledge of the interaction between technological processes and equipment.

4) The above knowledge helped us to solve the problem of manufacturing hybrid ICs in small runs economically. The small run demand is one of our specific characteristics.

5) We developed from the very beginning thin and thick film technologies in parallel. Also in thin film technology nichrome and tantalum nitride techniques are considered as complementary ones. Therefore both thin film systems and also thick film techniques are often used together in hybrid constructions.

\section{HIKI}

Within the complex Institute Factory, the task of the Institute extends from basic research, through design, development and pilot production of new hybrid circuits and systems to the development of the manufacturing processes. The main activities are therefore as follows:-

1) We do most of the basic research in connection with the different thin and thick film layers. We investigate the connection between quality and manufacturing conditions concerning principally the stability and TCR of the resistive layers. We examine the changes during oxidation in structure and composition of both nichrome and tantalum nitride films and the correlation between these changes and the electrical parameters. We do a lot of work on studying the microwave behaviour of different conductive thick films compared to plated thin gold layers. In all of these research works we make use of the modern surface physical testing facilities of the Hungarian universities and other research centres.

2) In our technological development work we rely upon the results of available scientific works. In order to decrease the effect of human factors on the quality of our products, and to save labour costs, one of our main tasks is the development of manufacturing processes, considering the demands of small runs.

3) Design work is the next subject. Most of the problems of our customers are characterized by parameters. The whole process of electrical and mechanical design is the task of our institute. Recently our users have given us more and more complex tasks and that means in some cases that almost a complete product can be using hybrid integrated techniques. To comply with all these requirements we deal systematically with some circuit design subjects such as converters, active RC filters, surface acoustic wave devices, high frequency active and passive circuits.

4) We endeavour to apply CAD/CAM techniques. CAD is already a common practice in our hybrid design. We are now trying to apply CAM to active trimming of the more sophisticated hybrid circuits. 
5) We regard it as our special duty to find all possible application fields of hybrid technology in Hungary. In the course of this sort of research work we meet some special problems and they need not only design-work but also specific development of construction and technology. These are the high frequency applications, automotive electronics and special high temperature applications. We develop hybrid systems for geophysical measuring purposes carried out in deep drillings. As the geothermic gradient in Hungary is unusually high this sets the experts and technology a specific task. Our special high temperature hybrid ICs work reliably at an ambient temperature of $180-200^{\circ} \mathrm{C}$. The steadily growing depth of deep drilling means increasing new problems for us in this respect. The production of hybrids in Hungary increases by $20-25 \%$ yearly.

6) In addition to research and development we have a pilot production plant in our institute. The aim of this small scale production is, in the first place, the practical control of the implementation of our research and development work. It gives us rectification opportunities and may be considered a training experience for large scale production. On the other hand the small scale production fulfils some permanent demands in relatively economical production situations.

Some examples of work at HIKI now follow.

\section{MICROSTRIP DESIGN}

Microstrip transmission lines are often used in high frequency hybrid circuits as matching and filter elements. It is very useful to know how to take into account the effect of the cover, and a method has been evolved for computing the minimum height of the cover.

A shielded microstrip of finite thickness is shown diagrammatically in Figure 1.

top cover

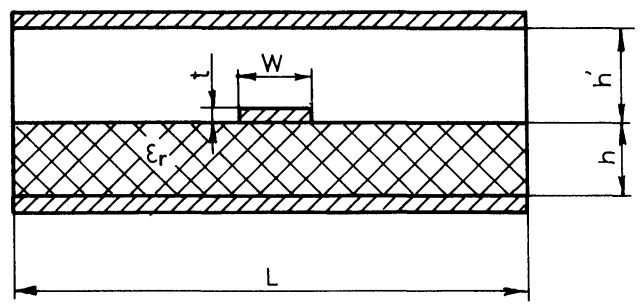

$H=h+h^{\prime}$
Approximating equations are available to compute $\mathrm{z}_{\mathrm{o}}$, the characteristic impedance, and $\epsilon_{\text {eff }}$ the effective dielectric coefficient of a shielded asymmetrical transmission line. ${ }^{1}$

These equations are:-

a) In the case of a narrow microstrip, $(w / h \leqslant 1)$

$$
\mathrm{z}_{\mathrm{o}}=\frac{60}{\sqrt{\epsilon_{\mathrm{eff}}}} \ln \left(\frac{8 \mathrm{~h}}{\mathrm{w}_{\mathrm{e}}}+\frac{\mathrm{w}_{\mathrm{e}}}{4 \mathrm{~h}}\right)-\mathrm{P}
$$

b) In the case of a wide microstrip ( $w / h>1)$,

$$
\begin{aligned}
& \mathrm{z}_{\mathrm{o}}=\frac{1}{\sqrt{\epsilon_{\mathrm{ff}}}} \\
& \frac{120 \pi}{\mathrm{w}_{\mathrm{e}} / \mathrm{h}+1.393+0.667 \ln \left[\mathrm{w}_{\mathrm{e}} / \mathrm{h}+1.44\right]}-\mathrm{Q}
\end{aligned}
$$

where:

$$
\begin{aligned}
& \epsilon_{\text {eff }}=\frac{\epsilon \mathrm{r}+1}{2}+\frac{\epsilon \mathrm{r}-1}{2}(\mathrm{~F}-\mathrm{C}) \\
& \tanh \left[0.18+0.235 \frac{\mathrm{h}^{\prime}}{\mathrm{h}}-\frac{0.415}{\left(\mathrm{~h}^{\prime} / \mathrm{h}\right)^{2}}\right] \\
& \mathrm{P}=270\left[1-\tanh \left(0.28+1.2 \sqrt{\mathrm{h}^{\prime} / \mathrm{h}}\right)\right], \\
& \mathrm{Q}=\mathrm{P}\left[1-\tanh \left(1+\frac{0.48\left(\mathrm{w}_{\mathrm{e}} / \mathrm{h}-1\right)^{1 / 2}}{\left(1+\mathrm{h}^{\prime} / \mathrm{h}\right)^{2}}\right)\right], \\
& \mathrm{W}_{\mathrm{e}}=\mathrm{w}+\frac{1.25}{\pi} \mathrm{t}\left(1+\ln \frac{2 \mathrm{x}}{\mathrm{t}}\right), \\
& \mathrm{F}=\left\{\begin{array}{l}
(1+12 \mathrm{~h} / \mathrm{w})^{-1 / 2}+0.04(1-\mathrm{w} / \mathrm{h})^{2} ; \text { if } \mathrm{w} / \mathrm{h} \leqslant 1 \\
(1+12 \mathrm{~h} / \mathrm{w})^{-1 / 2}
\end{array} ; \text { if } \mathrm{w} / \mathrm{h}>1\right.
\end{aligned}
$$

and

$$
\mathrm{x}=\left\{\begin{array}{r}
2 \pi \mathrm{w} ; \text { if } \pi \mathrm{w} / \mathrm{h} \leqslant 1 / 2 \\
\text { if } \pi \mathrm{w} / \mathrm{h}>1 / 2
\end{array} .\right.
$$

Applying an HP 9845T computer to evaluate these expressions, the results may be obtained very quickly. If $\mathrm{L} / \mathrm{H}>2.5$ and $\epsilon_{\mathrm{r}}>2.35$, then the finite $\mathrm{L}$ has a

FIGURE 1 
negligible effect on the microstrip. In order to determine the minimum height of the top cover, $h^{\prime}(\min )$, the characteristic impedances and the effective dielectric coefficients of four kinds of microstrips have been computed as a function of $h^{\prime}$. The ceramic substrate was LAVA Co $772, \epsilon_{\mathrm{r}}$, relative dielectric coefficient was 9.8 , and $\mathrm{h}=0.63 \mathrm{~mm}$. The height of top cover, $\mathrm{h}^{\prime}$ was changed from $2 \mathrm{~mm}$ to $20 \mathrm{~mm}$. The change of $Z_{o}$

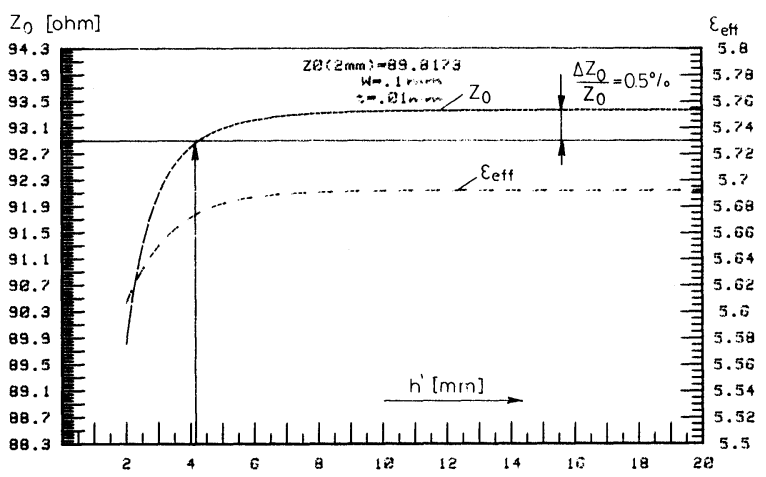

FIGURE 2

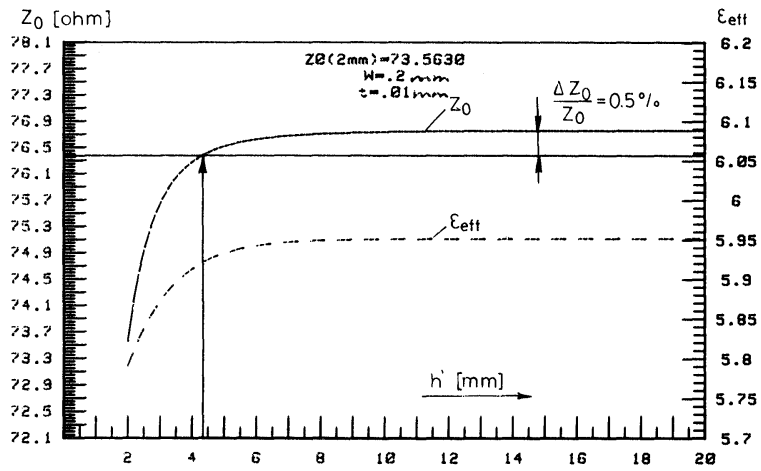

FIGURE 3

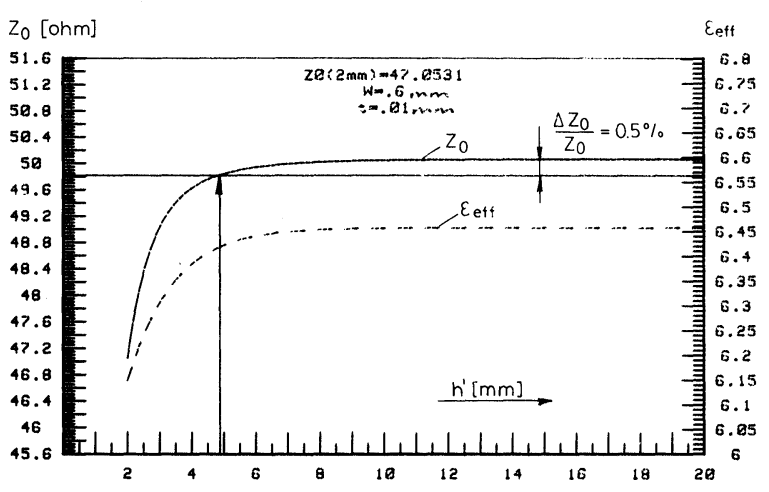

FIGURE 4

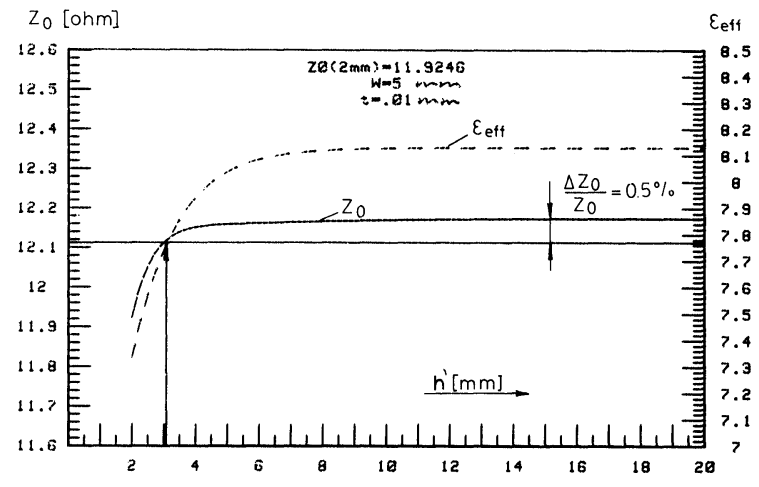

FIGURE 5

and $\epsilon_{\text {eff }}$ as a function of $h^{\prime}$ can be seen in Figures 2, 3, 4 , and 5 for the two different values of the strip width. In the case of $h^{\prime}=20 \mathrm{~mm}$ the effect of the cover is seen to be negligible.

In these figures arrows mark where the changes of characteristic impedances are $0.5 \%$, compared with the values of characteristic impedances at $h^{\prime}=20 \mathrm{~mm}$.

Generally $h^{\prime}$ was about $10 \mathrm{~mm}$ in our high frequency hybrid circuits and this value was enough to render negligible the effect of the top cover on the microstrip.

\section{DESIGN OF GAIN CONTROLLED AMPLIFIER}

There are many ways of obtaining wide band amplifiers with controlled gain. Some of the wellknown solutions are shown in Figures 6, 7 and 8.

A PIN diode attenuator and amplifier are connected in cascade in Figure 6. In this case three PIN diodes have to be controlled properly to set the matching and attenuation conditions.

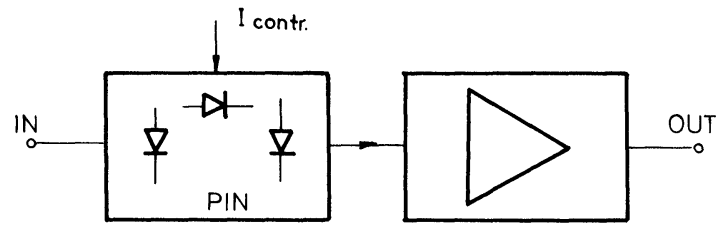

FIGURE 6

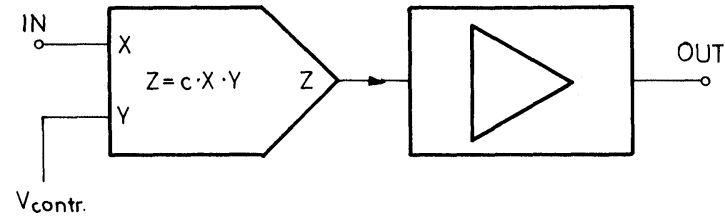

FIGURE 7 


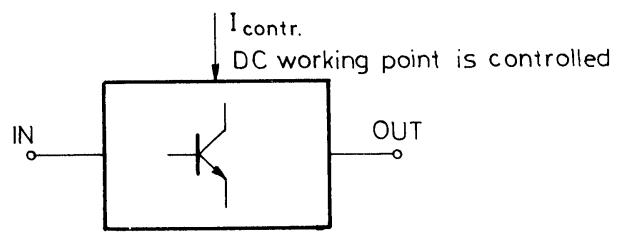

FIGURE 8

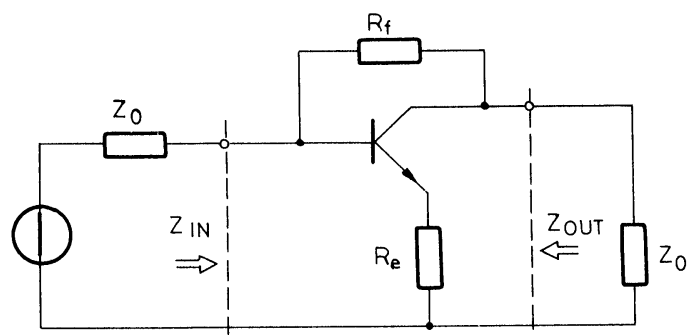

FIGURE 9

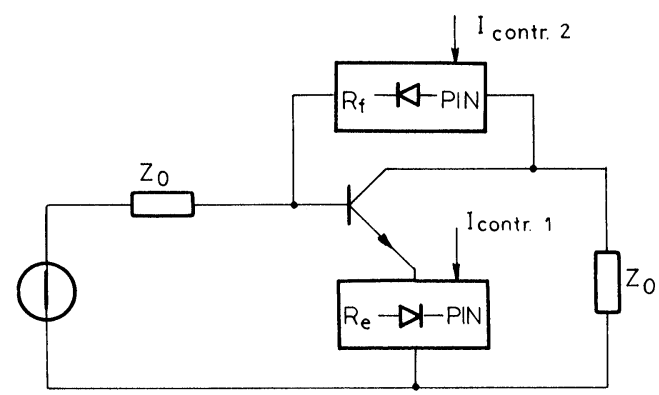

FIGURE 10

Multiplier and amplifier are connected in cascade in Figure 7. To realize this circuit one needs a very good multiplier to obtain linearity and a high frequency response.

The gain may be controlled by changing the DC working point of an active element. This is shown in Figure 8 . This solution is not a good one because the matching conditions and linearity are also changed during the regulation.

A further technique for obtaining a wide band amplifier with control is shown in Figure 9.

It is well-known that the common emitter configuration of a bipolar transistor is suitable for use in a wide band amplifier because it phase inverts and thus negative feedback may be easily included in the stage. The optimum bandwidth and matching can be reached by applying series and parallel feedback to the same stage. $^{2}$

Let the transistor be an ideal one.
Analysing this circuit, the matching condition, i.e. $\mathrm{z}_{\mathrm{o}}=\mathrm{z}_{\mathrm{IN}}=\mathrm{z}_{\text {OUT }}$ is the following:-

$$
z_{\mathrm{o}}=\sqrt{\mathrm{R}_{\mathrm{e}} \mathrm{R}_{\mathrm{f}}} .
$$

Supposing $\mathrm{S}_{21}$, the scattering parameter, can be computed as:

$$
S_{21}=\frac{R_{e}-R_{f}}{R_{e}+Z_{o}} .
$$

If $\mathrm{R}_{\mathrm{e}} \ll \mathrm{R}_{\mathrm{f}}$, then:

$$
S_{21}=-\sqrt{\frac{R_{f}}{R_{e}}} .
$$

In the case of matching, the $S_{12}$ scattering parameter may be determined by the following expression:

$$
S_{12}=\frac{R_{e}}{R_{e}+Z_{o}}
$$

A gain controlled wide band amplifier may be realised by connecting in PIN diodes instead of $R_{e}$ and $R_{\mathbf{f}}$, as shown in Figure 10.

A measure of the values of $S_{21}, S_{12}$ and the values of $R_{f}$ and $R_{e}$ are given in Table $I$.

The advantageous property of this circuit is its simplicity. The PIN diodes are easily controlled. It has to be mentioned that in the case of a high controlling range, the $S_{12}$ scattering parameter, may increase. Using the amplifier at high output voltage and low frequency the PIN diodes cause nonlinearities, so these are disadvantageous properties.

The schematic diagram of a controlled gain wide band amplifier that has been constructed is shown in Figure 11.

The gain is only partially controlled by the PIN diodes because in this case it is simpler to solve the DC setting of the PIN diodes and it is not necessary

TABLE I

The values of $S_{21}$ and $S_{21}$ as a function of $R_{f}$ and $\mathrm{R}_{\mathrm{e}}\left(\mathrm{z}_{\mathrm{o}}=50 \mathrm{ohm}\right)$

\begin{tabular}{llrrrrrr}
\hline & abs & 5 & 4 & 3 & 2 & 1 & 0.5 \\
$\mathrm{~S}_{21}$ & {$[\mathrm{~dB}]$} & 14 & 12 & 9.5 & 6 & 0 & -6 \\
& $0\left[^{\circ}\right]$ & 180 & 180 & 180 & 180 & 180 & 180 \\
\hline & abs & 0.143 & 0.167 & 0.2 & 0.25 & 0.333 & 0.4 \\
$\mathrm{~S}_{12}$ & {$[\mathrm{~dB}]$} & $\begin{array}{c}-16.9 \\
0\end{array}$ & $\begin{array}{c}-15.5 \\
0\end{array}$ & $\begin{array}{c}-14 \\
0\end{array}$ & $\begin{array}{c}-12 \\
0\end{array}$ & $\begin{array}{c}-9.5 \\
0\end{array}$ & $\begin{array}{c}-8 \\
0\end{array}$ \\
\hline $\mathrm{R}_{\mathrm{f}}$ & {$[\mathrm{ohm}]$} & 300 & 250 & 200 & 150 & 100 & 75 \\
$\mathrm{R}_{\mathrm{e}}$ & {$[\mathrm{ohm}]$} & 8.33 & 10 & 12.5 & 16.67 & 25 & 33.3 \\
\hline
\end{tabular}




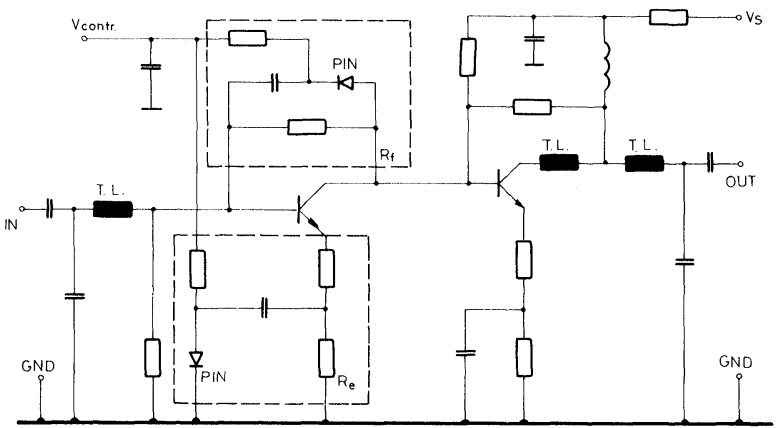

FIGURE 11

to control the PIN diodes exactly to obtain to the mathematical exact matching condition.

This circuit has been made by using thin film tantalum technology. Tantalum film with $50 \mathrm{ohm} /$ square sheet resistance is suitable for the resistor values required. The ohm/square of the conductors was decreased by electro plating with gold. The thickness of the Au film was about 5-10 um. The circuit was made by the usual photolithographic processes.

The final gain controlled amplifier is shown in Figure 12 packaged with SMC connectors. Some results obtained with this amplifier are shown in Table II.

The circuit was designed for use as a general purpose amplifier but it may be applied to other situations, e.g.: as a quasi-concentrated bandpass filter block.

A complete gain controlled bandpass circuit and its frequency response is shown in Figure 13.

In this figure the frequency response is normalised at $250.7 \mathrm{MHz}$, and the gain is $30 \mathrm{~dB}$ at this point. The

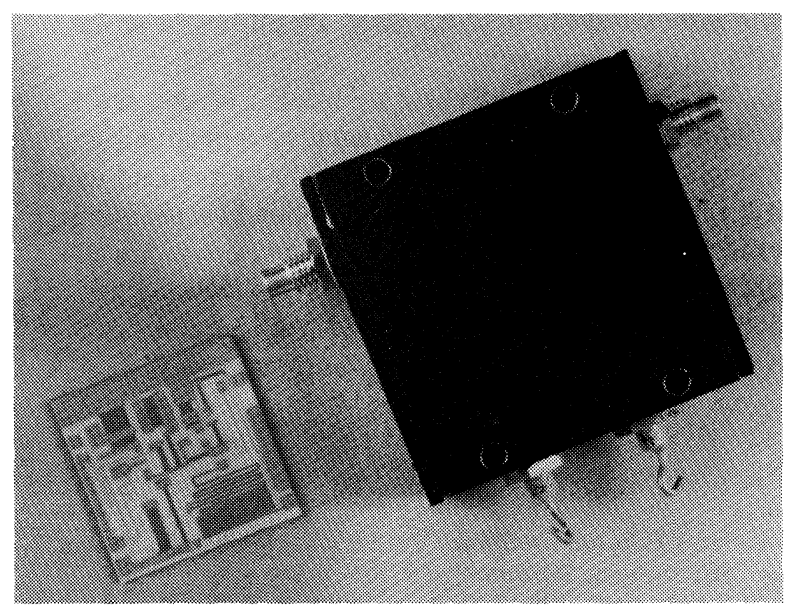

FIGURE 12

TABLE II

Reference data for the controlled gain amplifier

Frequency range

Source and load imp.

Standing wave ratio (input and output)

Transducer gain, $\mathrm{G}_{\text {tr }}$

$$
\text { at } \begin{aligned}
\mathrm{V} & =0 \mathrm{~V} \\
\text { at } \mathrm{V}_{\mathrm{c}} & =15 \mathrm{~V}
\end{aligned}
$$

Flatness of response, $\pm \Delta \mathrm{G}_{\mathrm{tr}}$

Output voltage, $\mathrm{V}_{\mathbf{O}}$

( $1 \mathrm{~dB}$ gain compression)

Supply, $\mathrm{V}_{\mathbf{s}}$

bandwidth of the amplifier is $\pm 2.5 \mathrm{MHz}$ and the range of regulation is $0 \ldots \pm 30 \mathrm{~dB}$. This selective amplifier has been used in radio equipment as an intermediate frequency unit.

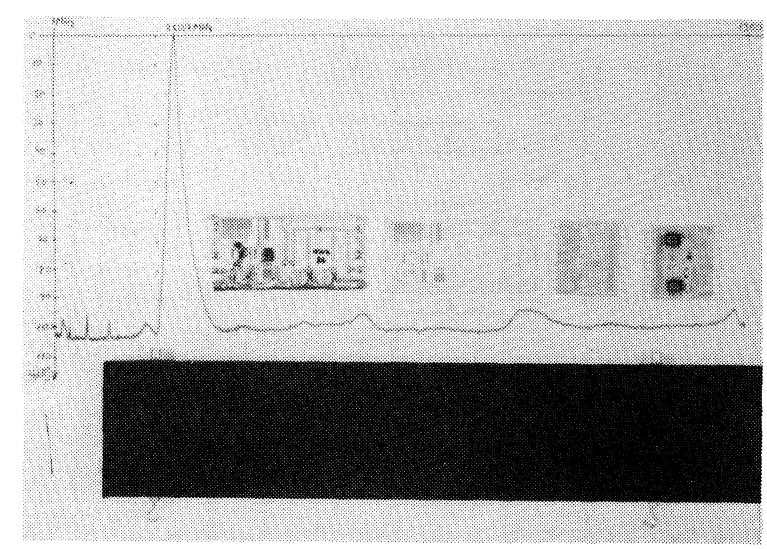

FIGURE 13

\section{OTHER APPLICATIONS}

\section{i) Switching matrix.}

The application fields of high frequency hybrid circuits are almost unlimited. For example hybrid techniques may be used in the video frequency stages, in the intermediate frequency circuits and in the microwave networks of a microwave relay station.

In such a station it is very useful to apply switching matrix networks because the video signal or intermediate frequency signal may be switched to anywhere and the switching time must be very short. A block scheme of a $4 \times 4$ intermediate frequency switching matrix is shown in Figure 14. The main parts of the matrix circuit have been made by hybrid technology. The frequency range is $70 \pm 15 \mathrm{MHz}$. 


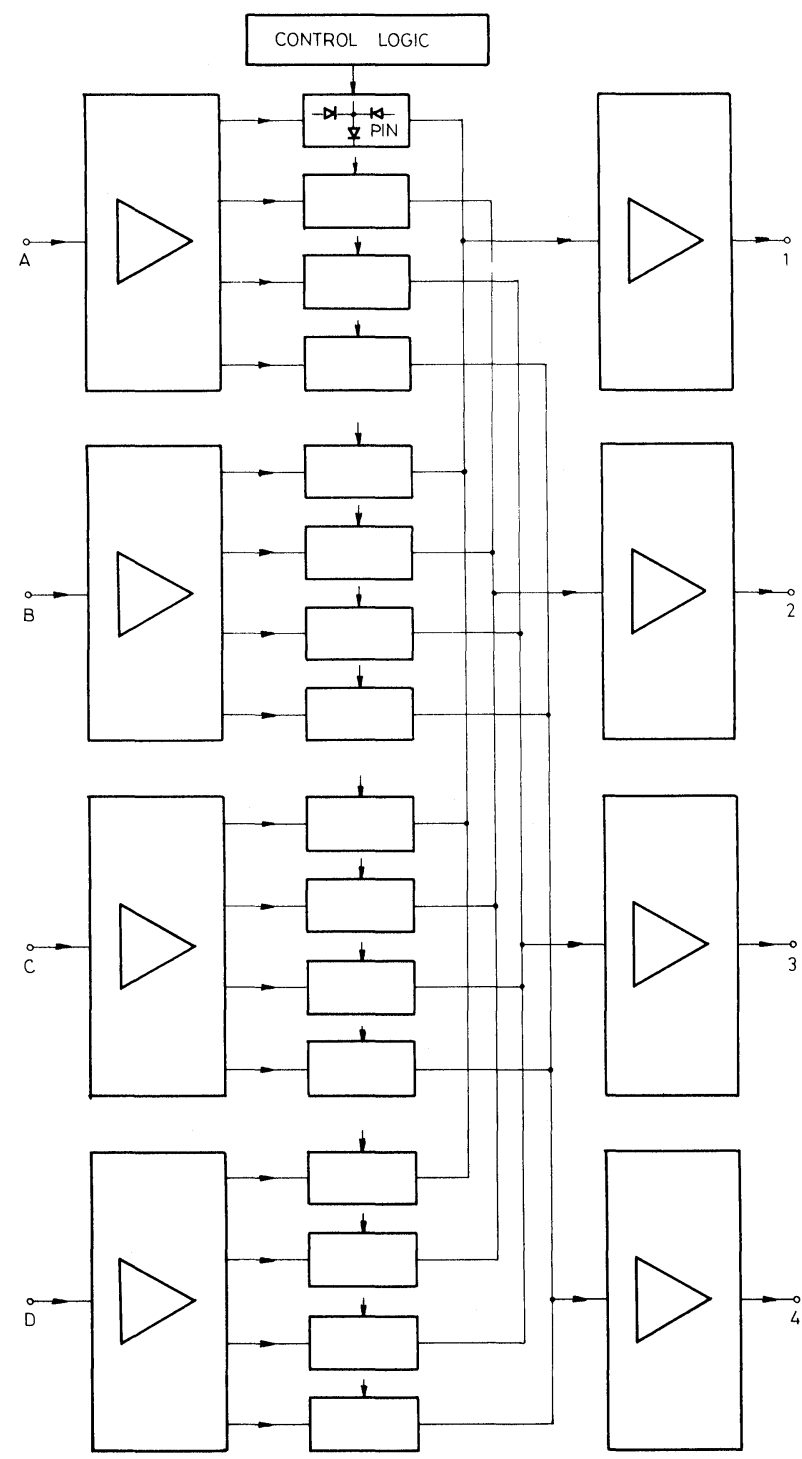

FIGURE 14

\section{ii) Attenuators.}

In order to measure gain precisely at high frequencies one needs exact high frequency attenuators. Attenuators with $\mathrm{N}$ type connectors are shown in Figure 15 made by thin film technology.

Microstrip terminating resistors are shown in Figure 16. The power dissipation is $3 \mathrm{~W}$.

\section{CONCLUSIONS}

This paper has shown the relationship established in

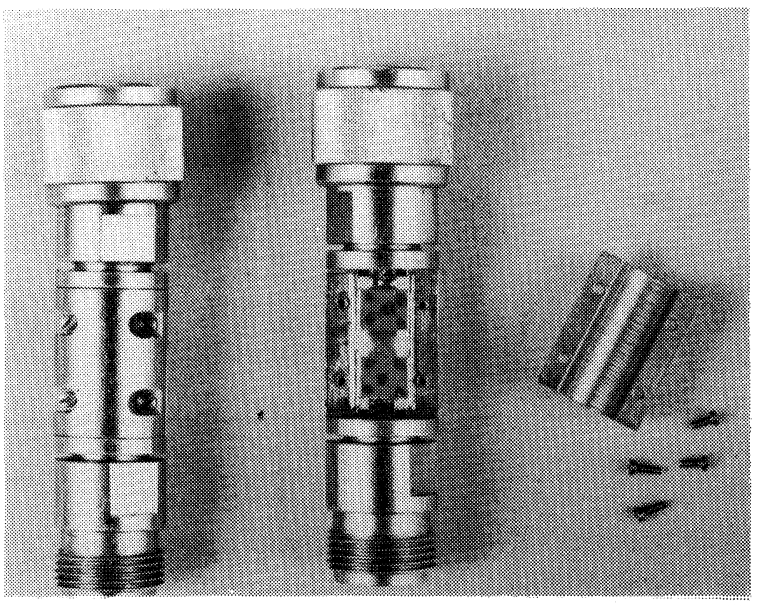

FIGURE 15

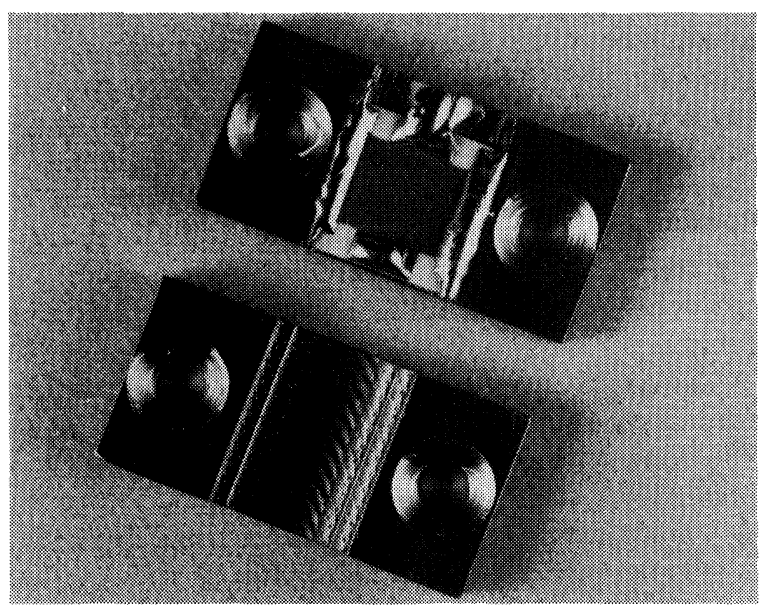

FIGURE 16

Hungary between the Research Institute, HIKI, and the associated factory, REMIX. Examples of work at HIKI have been given.

With reference to hybrid microelectronics, work at HIKI has shown that good quality reproducible low and high frequency circuits may be realised using hybrid integrated techniques. A hybrid technique is especially useful for making high frequency circuits because the size of hybrid circuits may be smaller compared with circuits mounted traditionally, and this way the parasitic elements are decreased.

\section{REFERENCES}

1. Dr. I.J. Bahl: Use Exact Methods for Microstrip Design, Microwaves, December, 1978.

2. Sturzu Petre: Use CAD to optimize broadband amp. design, Electronic Design, 10, May 10, 1974. 

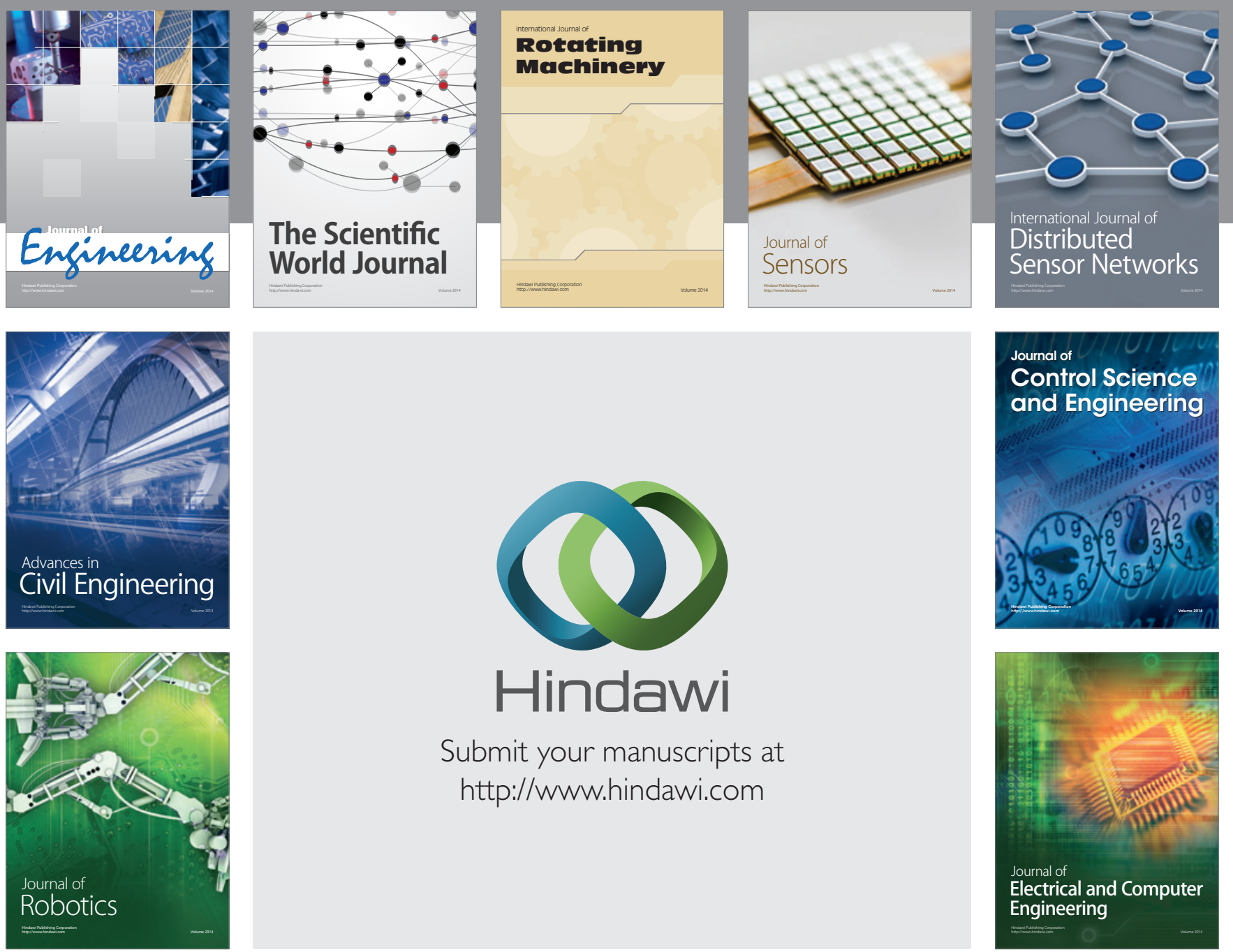

Submit your manuscripts at

http://www.hindawi.com
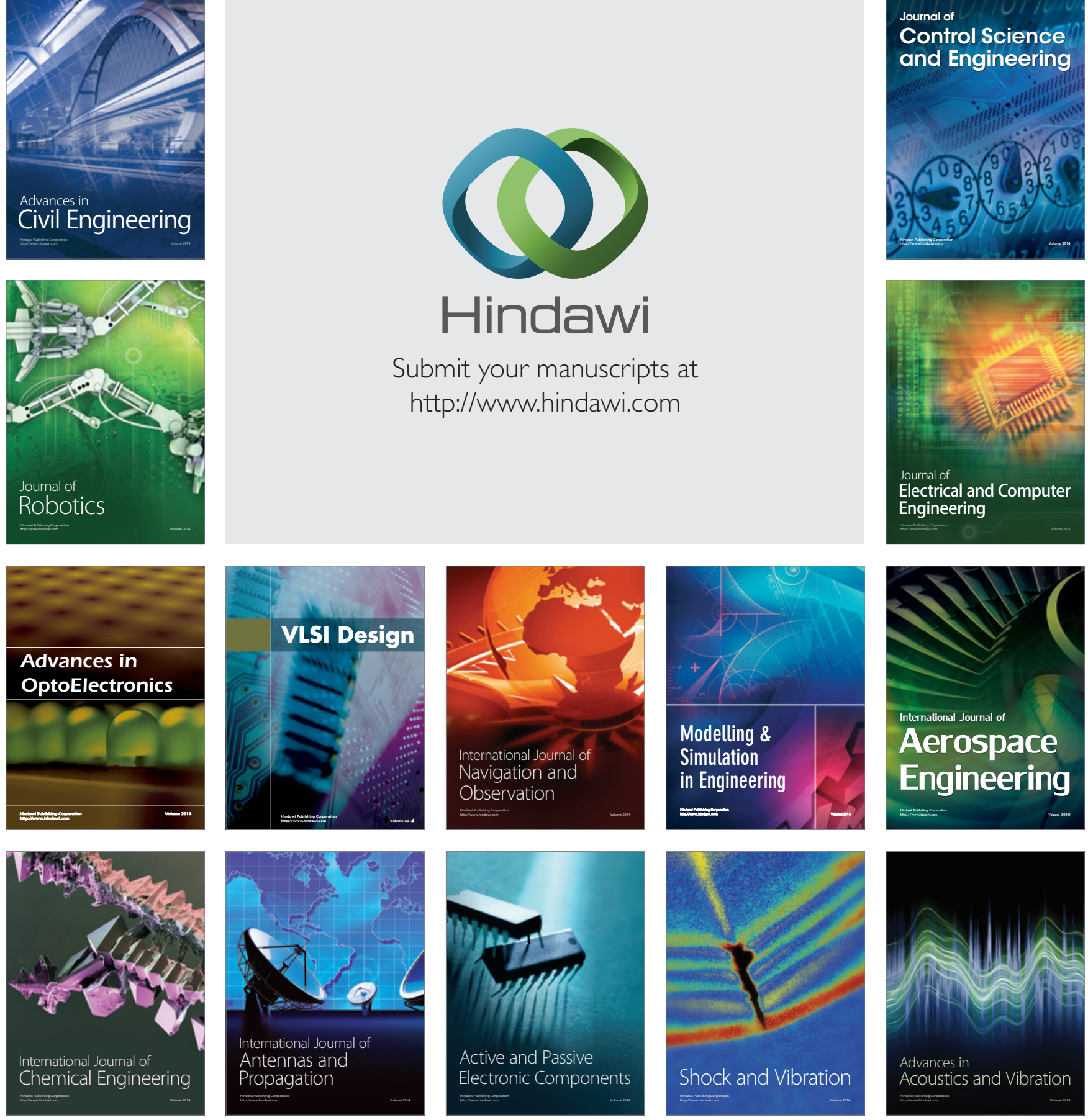